NASA

Technical Memorandum 106643

AIAA-94-2936
Army Research Laboratory Technical Report ARL-TR-478

\title{
Comparison of Gap Elements and Co
Algorithm for 3D Contact Analysis of Spiral Bevel Gears
}

G.D. Bibel

University of North Dakota

Grand Forks, North Dakota

K. Tiku and A. Kumar

University of Akron

Akron, Ohio

R. Handschuh

Vehicle Propulsion Directorate

U.S. Army Research Laboratory

Lewis Research Center

Cleveland, Ohio

Prepared for the

30th Joint Propulsion Conference

cosponsored by the AIAA, SAE, ASME, and ASEE

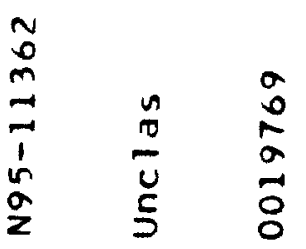

Indianapolis, Indiana, June 27-29, 1994

NASA

National Aeronautics and

Space Administration

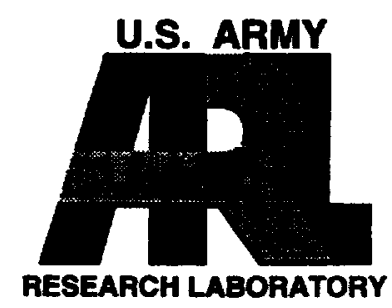




\title{
COMPARISON OF GAP ELEMENTS AND CONTACT ALGORITHM FOR 3D CONTACT ANALYSIS OF SPIRAL BEVEL GEARS
}

\author{
G. D. BLBEL \\ University of North Dakota \\ Grand Forks, North Dakota \\ K. TIKU and A. KUMAR \\ University of Akron \\ Akron, Ohio \\ R. HANDSCHUH \\ U.S. Army Vehicle Propulsion Directorate \\ NASA Lewis Research Center \\ Cleveland, Ohio
}

\begin{abstract}
Three dimensional stress analysis of spiral bevel gears in mesh using the finite element method is presented. A finite element model is generated by solving equations that identify tooth surface coordinates. Contact is simulated by the automatic generation of non-penetration constraints. This method is compared to a finite element contact analysis conducted with gap elements.
\end{abstract}

\section{Introduction}

Spiral bevel gears are used to transmit power between intersecting shafts. In helicopter transmissions these gears operate at very high speeds and transmit substantial power. To reduce vibration, noise and improve life, the stresses and deflections during meshing must be understood.

The finite element method (FEM) is particularly well suited to study tooth deflections, contact stresses and tooth fillet stresses. Much effort bas focused on predicting stresses in gears with FEM. Most of this research, to date, has been done on parallel axis gears with two dimensional geometry. Because of the difficulty of correctly identifying the three dimensional geometry, only a few researchers have investigated spiral bevel gears with FEM $[1,2]$.

Previously a single spiral bevel tooth has been analyzed with FEM [3], however in that analysis a contact stress distribution was assumed. To model the correct contact load distribution requires a gear and pinion loaded in mesh. In reference [4], a gearset in mesh was analyzed using gap elements to model the contact zones.
The research reported in this study will utilize the numerical solution for spiral bevel surface geometry with the automatic generation of non-penetration constraints to model the contacts during meshing. Pinion tooth and gear tooth surfaces will be developed based on the manufacturing kinematics. A multi-tooth model (4 gear and 3 pinion teeth) is created by replicating pinion and gear teeth in space with 2 solid modeler [10]. The results for the gap element model are compared to the nonpenetration constraint model.

\section{Tooth Surface Coordinate Equations}

The system of equations, required to define the coordinates of spiral bevel gear tooth surfaces, were derived in reference 3 , and are briefly summarized bere.

The first equation (equation of meshing) is based on the kinematics of manufacture and the machine tool settings. The equation of meshing requires the relative velocity between a point on the cutting surface and the same point on the pinion being cut must be perpendicular to the cutting surface normal.

where,

$$
\mathbf{n} \cdot \mathrm{V}=\mathbf{0}
$$

$\mathbf{n}$ is the normal vector from the cutter surface and

$\mathrm{V}$ is the relative velocity between the cutter and the workpiece surfaces at the specified location. This equation is developed in terms of machine tool parameters $U, \theta$ and $\phi_{c}$ where, $U$ and $\theta$ (length and rotational orientations) locate a point on the cutting head cone and $\phi_{k}$ is the rotated orientation of the cutter as it swings on the cradle. 
Since the kinematic motion of cutting a gear is equivalent to the cutting head meshing with a simulated crown gear, an equation of meshing can be written in terms of a point on the cutting head i.e, in terms of $U, \theta$ and $\phi_{c}$. The equation of meshing for straight sided cutters with a constant ratio of roll between the cutter and the workpiece is given by (ref. 5 ):

$$
\begin{gathered}
(U-r \cot \psi \cos \psi) \cos \gamma \sin \tau \\
+S\left(m_{c w}-\sin \gamma\right) \cos \psi \sin \theta \\
\mp \cos \gamma \sin \gamma \sin \left(q-\phi_{)}\right) \\
\pm E_{m}(\cos \gamma \sin \gamma+\sin \gamma \cos \gamma \cos \tau) \\
-L_{m} \sin \gamma \cos \psi \sin \tau=0
\end{gathered}
$$

The upper and lower signs are for left and right hand gears respectively. The following machine tool settings are defined:

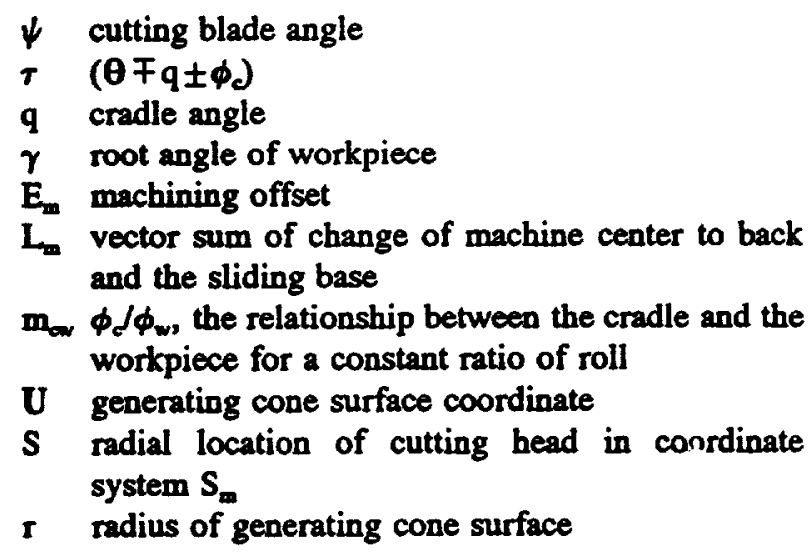

Equation (1) is equivalent to:

$$
f_{1}\left(U, \theta, \phi_{f}\right)=0
$$

Because there are three unknowns $U, \theta$, and $\phi_{c}$; three equations must be developed to solve for the surface coordinates of a spiral bevel gear. The three parameters $\boldsymbol{U}, \boldsymbol{\theta}$ and $\phi_{c}$ are defined relative to the cutting head and cradle coordinate systems $\left(S_{c}\right.$ and $\left.S_{\downarrow}\right)$ respectively. These parameters can be transformed through a series of coordinate transformations to a coordinate system attached to the workpiece [5]. Or U, $\theta$ and $\phi_{c}$ can be mapped into $X_{w}, Y_{m}, Z_{w}$ in coordinate system $S_{w}$ attached to the workpiece. These transformations, used in conjunction with two other geometric requirements, give the two additional equations.

The correct $U, \theta$ and $\phi_{c}$ that solves the equation of meshing, must also, upon transformation to the workpiece coordinate system $S_{w}$, result in a axial coordinate $\mathbf{Z}_{w}$ that matches with the value of $Z$ found by projecting the tooth face in the XY plane.

$$
z_{w}-Z=0
$$

This equation along with the correct coordinate transformations (see Equation 10) result in a second equation of the form:

$$
f_{2}\left(U, \theta, \phi_{c}\right)=0
$$

A similar requirement for the radial location of a point on the workpiece results in the following:

$$
r-\sqrt{\left(X_{w}^{2}+Y_{w}^{2}\right)}=0
$$

These projections are as shown in figure 1. The appropriate coordinate transformations (see Equation 10) will convert equation 6 into a function of $U, \theta$ and $\phi_{c}$

$$
f_{3}(U, \theta, \phi)=0
$$

Equations (2), (4), (6) form a system of nonlinear equations necessary to define a point on the tooth surface.

\section{Solution Technique}

Equations (2), (4), (6) form a nonlinear system of equations that do not have a closed form solution. They are solved using Newton's method (ref. 8).

An initial guess $U_{0}, \theta_{0}, \phi_{\infty}$ is used to the start iterative solution procedure. Newton's method is used to determine subsequent values of the updated vector $\left(U_{k}\right.$, $\left.\theta_{k}, \phi_{\alpha}\right)$.

$$
\left[\begin{array}{l}
U_{k} \\
\theta_{k} \\
\phi_{k}
\end{array}\right]=\left[\begin{array}{l}
U_{k-1} \\
\theta_{k-1} \\
\Phi_{k-1}
\end{array}\right]+\left[\begin{array}{c}
Y_{k-1}^{1} \\
Y_{k-1}^{1} \\
Y_{k-1}^{1}
\end{array}\right]
$$

where the vector $\mathbf{Y}$ is the solution of:

The $3 \times 3$ matrix in the preceding equation is the Jacobian matrix and must be inverted each iteration to solve for the

$$
\left[\begin{array}{l}
\frac{\partial f_{1}\left(U^{k-1}\right)}{\partial U} \frac{\partial f_{1}\left(\theta^{k-1}\right)}{\partial \theta} \frac{\partial f_{1}\left(\phi_{c}^{k-1}\right)}{\partial \phi_{c}} \\
\frac{\partial f_{2}\left(U^{k-1}\right)}{\partial U} \frac{\partial f_{2}\left(\theta^{k-1}\right)}{\partial \theta} \frac{\partial f_{2}\left(\phi_{c}^{k-1}\right)}{\partial \phi_{c}} \\
\frac{\partial f_{3}\left(U^{k-1}\right)}{\partial U} \frac{\partial f_{3}\left(\theta^{k-1}\right)}{\partial \theta} \frac{\partial f_{3}\left(\phi_{c}^{k-1}\right)}{\partial \phi_{c}}
\end{array}\right]\left\{\begin{array}{l}
Y_{1}^{k-1} \\
Y_{2}^{k-1} \\
Y_{3}^{k-1}
\end{array}\right\}=\left\{\begin{array}{l}
f_{1}\left(U^{k-1}, \theta^{k-1}, \phi_{c}^{k-1}\right) \\
f_{2}\left(U^{k-1}, \theta^{k-1}, \phi_{c}^{k-1}\right) \\
f_{3}\left(U^{k-1}, \theta^{k-1}, \phi_{c}^{k-1}\right)
\end{array}\right\}
$$


$Y$ vector. The equation of meshing, function $f_{1}$, is numerically differentiated directly to find the terms for the Jacobian matrix. Function $f_{2}$ and $f_{3}$ cannot be directly differentiated with respect to $U, \theta$ and $\phi_{c}$. After each iteration $U^{k-1}, \theta^{k-1}, \phi_{c}^{k-1}$ (in the cutting head coordinate system) are transformed into the workpiece coordinate system, $\mathbf{S}_{w}$, with the series of coordinate transformations as given in Equations 9 and 10 . (The right side of equation 9 locates a point on the cutting head cone as shown in figure 2.)

$$
\left[\begin{array}{l}
X_{w} \\
Y_{w} \\
Z_{w} \\
1
\end{array}\right]=\left[M_{w}\right]\left[\begin{array}{c}
r \cot \psi-U \cos \psi \\
U \sin \psi \sin \theta \\
U \sin \psi \cos \theta \\
1
\end{array}\right]
$$

where,

$$
\left.\left[M_{w c}\right]=\left[M_{m o} f\left(\Phi_{c}\right)\right]\left[M_{\alpha p}\right]\left[M_{p m}\right]\left[M_{w 0} f\left(\phi_{c}\right)\right] M_{\alpha c}\right]
$$

The matrix $\left[\mathrm{M}_{\mathrm{mc}}\right]$ above represents a series of homogeneous coordinate transformations from a coordinate on the cutting head onto a coordinate system on the workpiece [5].

Functions $f_{2}$ and $f_{3}$ are evaluated by starting with an initial $U_{k}, \theta_{k}$ and $\phi_{k}$, performing the transformations in Equation (10) and evaluating Equations (4) and (6). The numerical differentiation of $f_{2}$ and $f_{3}$ is performed by transforming $U_{k}+$ inc, $\theta_{k}+$ inc, $\phi_{k}+$ inc (where inc is a small increment appropriate for numerical differentiation) into $X_{w}+$ inc, $Y_{w}+$ inc, $Z_{w}+$ inc. Equations (4) and (6) are then used to evaluate the numerical differentiation. Function $f_{1}, f_{2}, f_{3}$ and their partial derivatives are required for the Jacobian matrix and are updated each iteration. The iteration procedure continues until the $Y$ vector is less then a predetermined tolerance. This completes the solution technique for a single point on the spiral bevel gear tooth surface. In this way the coordinates of the surface of the tooth are defined. This solution technique is repeated for each of the four surfaces; gear convex, gear concave, pinion convex and pinion concave.

Since all four surfaces are generated independently, additional matrix transformations are required to obtain the correct tooth thickness. The concave surfaces are fixed on each tooth. The convex surfaces are rotated as required. The angle of rotation is obtained by matching the tooth top land thickness with the desired value.

\section{Gear and Pinion Orientations Required for Meshing}

When generating the pinion and gear surface as described above, the pinion cone and gear cone apex will meet at the same point. This point is the origin of the fixed coordinate system attached to the workpiece being generated. To place the gear and pinion in mesh with each other, rotations described in the following example are required (ref. 6).

1. The gear tooth surface points are rotated by $360 / N_{t}+180 \mathrm{CW}$ about the global $\mathrm{Z}_{\mathrm{w}}$ axis, for this example, the rotation is 190 degrees.

2. The pinion is rotated by $90 \mathrm{deg} \mathrm{CCW}$ about the global $\mathrm{Y}$ axis.

3. Because the four surfaces are defined independently, their orientation is random with respect to meshing. The physical location of the gear and pinion after rotations described above correspond to the gear and pinion overlapping. To correct this condition the pinion is rotated CW about its axis of rotation $Z_{w}$ until surface contact occurs. For the example used in this study, the rotation was $3.56 \mathrm{deg}$.

To make a complete pinion, the generated pinion tooth was copied and rotated 12 times and the generated gear tooth was copied and rotated 36 times with the aid of a solid modelling program as shown in figure 3.

\section{Finite Element Analysis of Spiral Bevel Gears}

Recent finite element analysis research on spiral bevel gears has attempted to solve the contact stress distribution in a multi-tooth model (4 gear and 3 pinion teeth) (ref. 4). The tooth pair contact zones in reference 3 were modeled with gap elements. In the current study, use of software with automated contact options is used. This is done to avoid certain limitations in the use of gap elements, such as:

(i) Difficulties in connecting the gap elements with proper orientations.

(ii) The orientation of the contact plane remains unchanged during deflection.

(iii) Difficult to accurately select the properties such as appropriate open/closed stiffness values, 
selection of the stiffness matrix update strategy and efficient problem restarts.

New advances in the state of the art for FEM provide deformable body against deformable body penetration algorithms which can be used to establish the nonlinear boundary conditions for contact problems. MARC (ref. 9) is one such FEM package software which uses this algorithm to automatically detect contact.

\section{Automated Contact Analysis}

Situations in which contact occurs are common to many different nonlinear applications. Contact forms a distinctive and important subset to the category of changing-status nonlinearities. Contact, by its very nature, is a nonlinear problem. During contact, both the forces transmitted across the area and the area of contact change. The force-displacement relationship thus become nonlinear. Usually, the transmitted load is in the normal direction.

The program used MARC (ref. 9), is a general purpose computer program for linear and nonlinear stress and beat transfer analysis. This program is capable of solving problems with nonlinearities that occur due to material properties, large deformations, or boundary conditions. In general, the solution of nonlinear FEM problems requires incremental solution schemes and sometimes requires iterations within each load/time increment to satisfy equilibrium conditions at the end of each step.

The FEM program used has a fully automatic contact option which enables the analysis between finite element bodies without the use of any special gap or contact elements. The contact option was originally designed for analysis of manufacturing processes such as forging or sheet metal forming, but its capabilities have been expanded to meet other analysis requirements. The work presented here utilized the program of reference 9 running on a supercomputer.

Contact between the bodies is handled by imposing nonpenetration constraints. The non-penetration constraint, as shown in figure 4 and figure 5 is:

$$
\mathbf{U}_{\mathbf{A}} \bullet \mathbf{n}<\mathbf{D}
$$

where: $U_{A}$ is the displacement of node $A$, $\mathrm{n}$ is normal to the contacted surface, $D$ is the contact tolerance
Solver constraints are used to impose the non-penetration constraint, and a very efficient surface contact algorithm which allows the user to simulate general 2D/3D multibody contact. Both "deformable-to-rigid" and "deformable-to-deformable" contact situations are allowed. The user needs to only identify which bodies might come in contact during the analysis. The bodies can be either rigid or deformable, and the algorithm tracks variable contact conditions automatically. Thus, the user no longer needs to worry about the location and open/close status checks of "gap elements". Automatic, in this context, means that user interaction is not required in treating multibody contact and friction, and the program has automated the imposition of non-penetration constraints.

Real world contact problems between rigid and/or deformable bodies are actually 3D in nature. To solve such contact problems, one needs to define bodies and their boundary surfaces.

Deformable bodies are defined by the elements of which they are made. Once all the boundary nodes for a deformable body are determined, 4 point patches are automatically created, which are constantly updated with the body deformation. Contact is determined between a node and all body profiles, deformable or rigid.

The user must define bodies so that their boundary surfaces can be established. Deformable bodies are defined by a list of finite elements. Because the contact boundary conditions are a function of the applied load, the analysis must be carried out incrementally. Within each load or time increment of an analysis, additional iterations may be required to stabilize the contact zone. Contact problems involve two important aspects:

(i) the opening and closing of the gap between bodies

(ii) friction between the contacting surfaces.

The MARC program establishes a hierarchy between the bodies so that at a given contact interface, one body is the contactor and the other body is the contacted. The set of nodes on the boundary surface of a contactor are candidate nodes for contact. The boundary surface of a contacted body is defined by a set of geometrical entities. A user specified contact tolerance is used to determine the body separation distance which determines whether two bodies are considered to be in contact with each other. The contactor's boundary nodes are prevented from penetrating the surface of the contacted body by imposing 
solver constraints. For contact between two deformable bodies, MARC applies multipoint constraints in the form of ties. The ties link the motion of one node on the contactor body to two adjacent nodes on the contacted body. During each iteration as nodes enter and leave contact or slide between adjacent node segments on contacted bodies, a bandwidth optimization is performed to reduce the computer processing time required.

A static analysis of two bodies that are not initially connected poses special problems with a FEM, if one of the bodies has a rigid body motion component. If, at any time, the two bodies are disconnected then the stiffness matrix would become singular and unsolvable (in a static analyses). In order to overcome this difficulty, the two gears are connected with weak springs. The spring stiffness must be negligible compared to the material stiffness.

\section{Model descriptions}

Pinion and gear design data and generation machine settings are as shown in Tables I and II. This information is used as input into a computer program that solves the 3 nonlinear equations (previously described) used to define the points on the pinion and gear surface. The program generates a NxM mesh on the tooth profile of a spiral bevel gearset [7]. After one gear and one pinion tooth was made, the geometric modeler [10] was used to rotate the teeth to create 4 gear teeth and 3 pinion teeth in mesh. Eight noded, isoparametric 3D brick elements were used. The seven tooth model is as shown in figure 6. The seven tooth model consisted of 8793 elements and 11261 nodes.

\section{Loading and Boundary Conditions}

The boundary conditions for the seven tooth model are also shown in figure 6 . The boundary conditions are applied such that the gear teeth are made to pivot about a fixed point along the axis of rotation for the gear on the $Z$ axis. The nodes where the forces are applied are in the hub of the gear. Fixed displacement boundary conditions are applied at $\mathbf{8}$ nodal points in the $Z$ direction only for the gear and in all directions for the pinion as shown in figure 6. Since this is a static problem involving two bodies (the pinion and the gear) in contact, as described in a previous chapter, weak springs are added to prevent the rotational rigid body modes for the gear. Eight springs are added away from the contact region. The springs connect the corner nodes of the pinion with the corner nodes of the gear on the faces where contact occurs. The stiffness of the springs are $100 \mathrm{lbs} / \mathrm{in}$. This is insignificant when compared to the tooth contact stiffness and therefore does not effect the overall solution. The maximum torque for the gear mesh studied was 9508 in. $-1 b s$. On the gear. This torque is applied as a concentrated force with a moment arm on the gear hub. This concentrated force for the seven tooth model was 4714 lbs. with a moment arm of 2.017 inches. The force is applied incrementally for convergence to occur.

\section{Gap Element and Automated Contact Analysis Comparison}

Contact stresses on spiral bevel gears were studied by researchers with gap elements in references 11 and 12 on a similar seven tooth model, comparison of the results with automated contact analysis is presented. Both models contained the same mesh density, boundary conditions, material properties and loading. The nodal stress results of pinion tooth \#1 obtained from automated contact analysis and gap elements are as shown in figures 7 and 8, respectively. In both analyses the highest concentrated stress value occur at the same node. Comparison of the results of these two runs are as follows.

\begin{tabular}{|l|c|c|}
\cline { 2 - 3 } \multicolumn{1}{c|}{} & Gap Element & $\begin{array}{c}\text { Automated } \\
\text { Contact Analysis }\end{array}$ \\
\hline $\begin{array}{l}\text { Min nodal prixcipal } \\
\text { atress }\end{array}$ & $-296,410$ (psi) & $-291,503$ (psi) \\
\hline CPU time (approx) & $30 \mathrm{~min}$. & $80 \mathrm{~min}$. \\
\hline $\begin{array}{l}\text { Elemental principal } \\
\text { stress }\end{array}$ & $-84,761$ (psi) & $-113,577$ (psi) \\
\hline $\begin{array}{l}\text { Gap element closed or } \\
\text { nodal points with contact }\end{array}$ & 4 & 8 \\
\hline No. of iterations & 4 & 8 \\
\hline
\end{tabular}

The nodal stresses were in very good agreement for both the gap element FEM and the automated contact FEM model. Elemental and nodal stresses differed greatly for both models indicating a need for mesh refinement. The gap element model, as expected, used less cpu time. More information is given by virtue of locating and defining the gap elements. This reduced the computational time required to search for and calculate the contact area and stresses. However, as noted earlier, it is much more difficult to calculate the proper orientation and location of the gap elements. It is more convenient to analyze contact with the automatic contact FEM program. 
The number of contact nodes at the contact region in the automated contact FEM program was higher than identified by the gap element FEM program. With the pinion considered body 1 (contactor body) and the gear considered body 2 (contacted body), eight nodes contacted as shown above. With body 1 and body 2 switched, 16 nodes were found to have contact. Presumably this sort of discrepancy occurred because the mesh was too coarse.

\section{CONCLUSIONS}

Three-dimensional contact analysis of spiral bevel gears in mesh was performed. Four gear teeth and three pinion teeth, generated by solving equations based on gear manufacturing kinematics, were used to model contact. An automatic contact analysis algorithm is utilized with the finite element method. The contact algorithm searches for and finds contact without using gap elements.

Comparison of nodal and elemental principal stresses is favorable with a previous FEM that utilized gap elements. However, for both models the nodal and elemental stresses were significantly different. Also, both models had large stress gradients at the contact point. This indicates that a more refined finite element mesh is required.

The contact algorithm model takes more cpu time compared to the gap element model. The contact algorithm has to find where contact occurs, with gap elements contact is defined to occur at the gap elements.

Although the gap element modal ran with less cpu time, use of the contact algorithm is more convenient. The contact algorithm is easier because gap elements do not bave to be mathematically defined in space with proper orientation.

\section{BIBLIOGRAPHY}

1. Choa, H.C., Baxter, M., Cheng, H.S., "A Computer Solution for the Dynamic Load, Lubricant Film Thickness, and Surface Temperatures in Spiral Bevel Gears," Advances Power Transmission Technology, NASA CP-2210, AVRODCOM TR-82-C-16, Fisher, G.K., \&., 1981, pp 345-346.

2. Drago, R.J., Uppaluri, B.R., "Large Rotorcraft Transmission Technology Development Program, vol. I, Tech Report, (D210-11972-1-vol-1, Boeing Vetrol Co., NASA Contract NAS3-22143) NASA CR-
$168116,1983$.

3. Handschuh, Robert F., Litvin, Fador L., "A Method for Determining Spiral-Bevel Gear Tooth Geometry for Finite Element Analysis," NASA TP-3096 AVSCOM TR-91-C-020, August 1991.

4. Bibel, G.D., Kumar, A., Reddy S., Handschuh R., "Contact Stress Analysis of Spiral Bevel Gears Using Nonlinear Finite Element Analysis," 29th Joint Propulsion Conference by AIAA, SAE, ASME, ASEE, June 1993.

5. Litvin, F.L., Tsung, W.J., Lee, H.T., "Generation of Spiral Bevel Gears with Conjugate Tooth Surfaces and Tooth Contact Analysis," NASA CR-4259, AVSCOM TR 87-C-22, 1987.

6. Kumar, A., Bibel, G.D., "A Procedure for Finite Element Analysis of Spiral Bevel Gears," NASA Contractor report (in press).

7. Bibel, G.D., Reddy, S., Kumar, A., "Manual for Automated Generation of Spiral Bevel Gears, " NASA Contractor Report (in press).

8. Burden, R.L., Fairies, D.J., Numerical Analysis, 3rd Edition, PWS Publishers, 1985.

9. MARC K-5.1 User Manual, MARC Analysis Research Corporation, Palo Alto, California, 1981.

10. PATRAN Users Manual, PDA Engineering, Costa Mesa, CA., July 1987.

11. Reddy, S., "Finite Element Analysis and Tooth Contact Analysis of Spiral Bevel Gear," Master's Thesis, submitted to the University of Akron, December 1992.

12. Kumar A., "Spiral Bevel Gear Contact 'Simulation and Stress Analysis' Using Finite Element Analysis," Master's Thesis submitted to the University of Akron, May 1993. 
TABLE I: PINION AND GEAR DESIGN DATA

\begin{tabular}{|l|l|l|}
\hline \multicolumn{1}{|c|}{ PINION } & \multicolumn{1}{|c|}{ GEAR } \\
\hline \hline Number of teeth pinion & 12 & 36 \\
\hline Dedundum angle, degree & 1.5666 & 3.8833 \\
\hline Addendum angle, degree & 3.8833 & 1.5666 \\
\hline Pitch angle, degree & 18.4333 & 71.566 \\
\hline Shaft angle, degree & 90.0 & 90.0 \\
\hline Mean spiral angle, degree & 35.0 & 35.0 \\
\hline Face width, mm (in) & $25.4(1.0)$ & $25.4(1.0)$ \\
\hline Mean cone distance, mm (in) & $81.05(3.19)$ & $81.05(3.19)$ \\
\hline Inside radius of blank, mm (in) & $5.3(0.6094)$ & $3.0(.3449)$ \\
\hline Top land thickness, mm (in) & $2.032(0.080)$ & $2.489(0.098)$ \\
\hline Clearance, mm (in) & $0.762(0.030)$ & $0.929(0.0366)$ \\
\hline
\end{tabular}

TABLE II: GENERATION MACHINE SETTINGS

\begin{tabular}{|c|c|c|c|c|}
\hline & \multicolumn{2}{|c|}{ PINION } & \multicolumn{2}{|c|}{ GEAR } \\
\hline & CONCAVE & CONVEX & CONCAVE & CONVEX \\
\hline Radius of cutter, $r$, in & 2.965 & 3.0713 & 3.0325 & 2.9675 \\
\hline Blade angle, $\psi$, degree & 161.954 & 24.3374 & 158.0 & 22.0 \\
\hline Vector sum, Lu & 0.0385 & -0.0518 & 0.0 & 0.0 \\
\hline Machine offset, $E_{m}$ & 0.1545 & -0.1742 & 0.0 & 0.0 \\
\hline Cradle to cutter distance, $s$, in & 2.947 & 2.8010 & 2.2859 & 2.2859 \\
\hline Cradle angle, $q$, degree & 63.94 & 53.926 & 59.2342 & 59.2342 \\
\hline Ratio of roll, $\mathrm{M}_{\mathrm{ow}}$ & 0.3083 & 0.3220 & 0.9508 & 0.9508 \\
\hline Initial cutter length, $u$, in & 9.5970 & 7.4253 & 8.1260 & 7.8915 \\
\hline Initial cutter orientation, $\theta$, degree & 126.8354 & 124.4368 & 223.9899 & 234.9545 \\
\hline Initial cutter orientation, $\phi_{c}$, degree & -0.8581 & -11.3866 & -0.3506 & -12.3384 \\
\hline
\end{tabular}




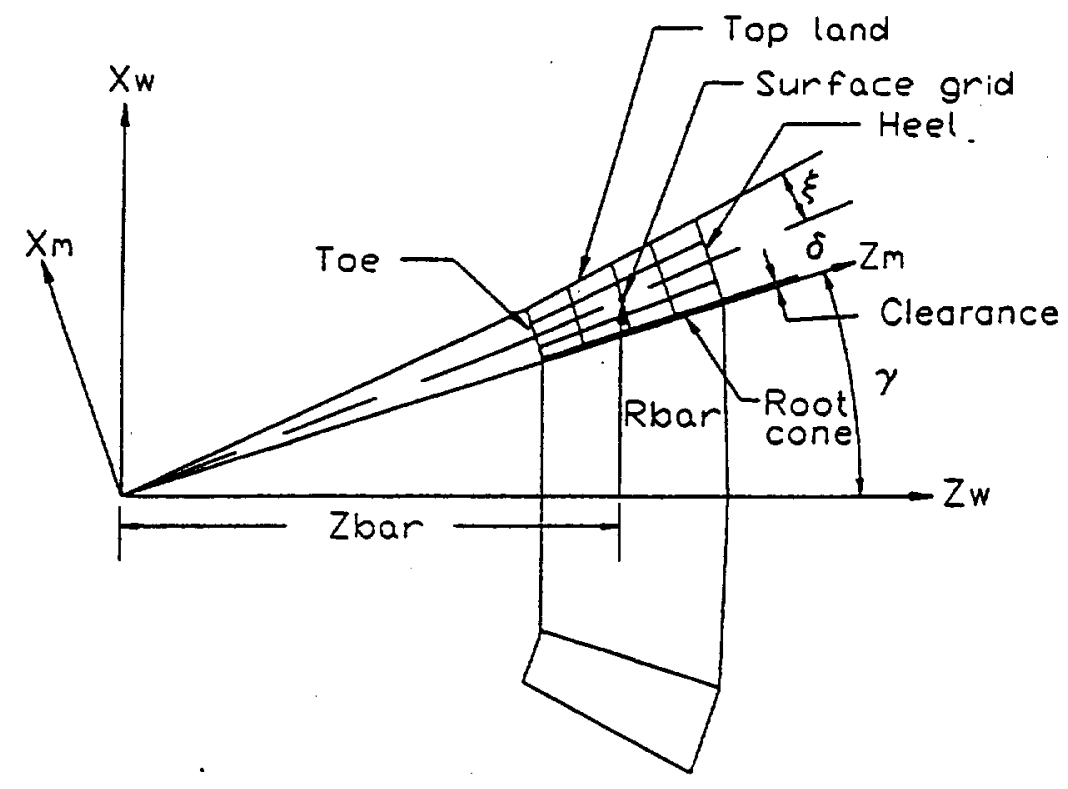

Figure 1. Projection of gear tooth into the XZ plane

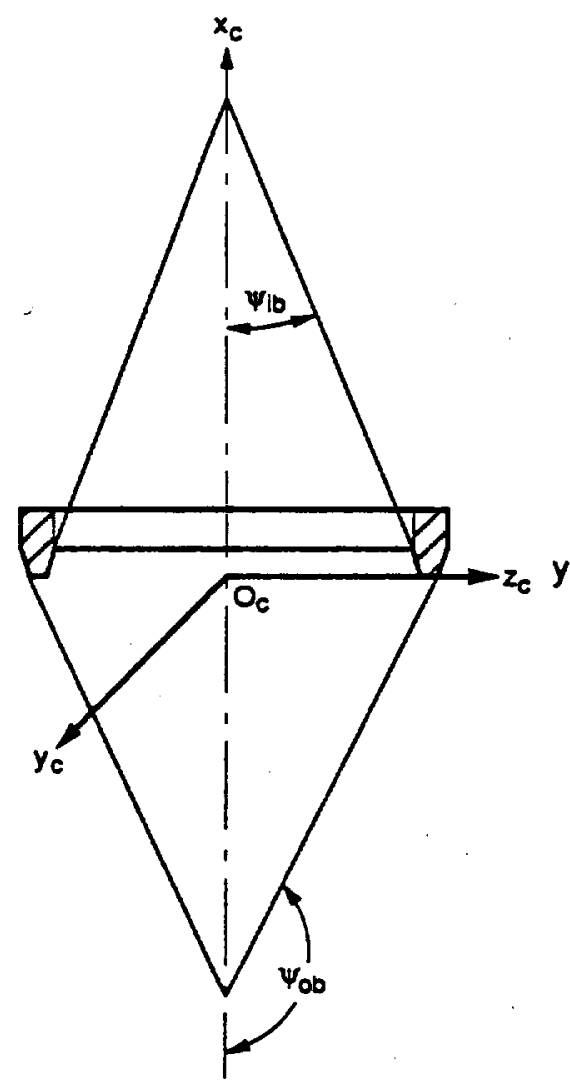

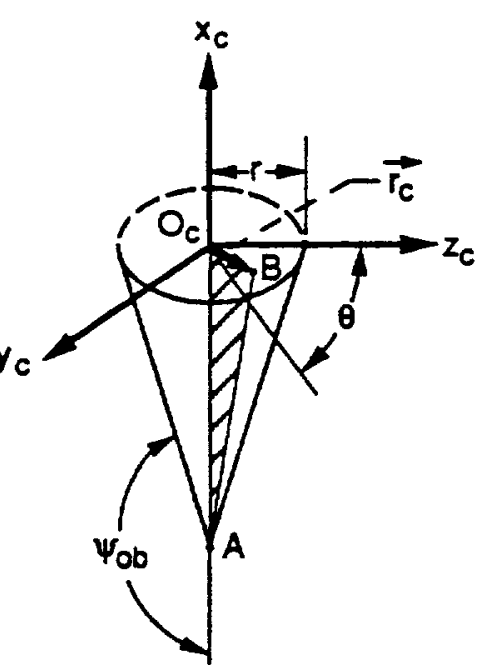

Outside blade (concave side);

$$
u=|\overline{A B}|
$$

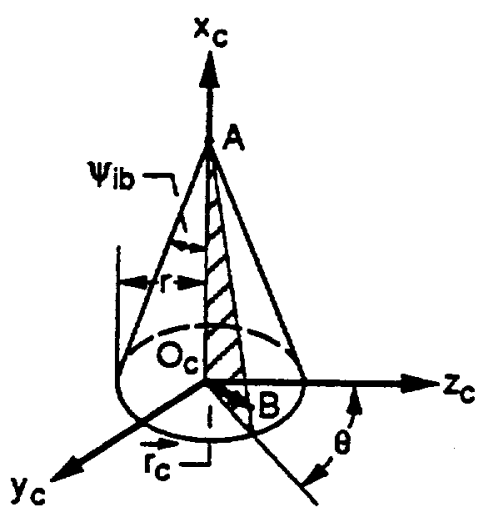

Inside blade (convex side);

$u=|\overline{A B}|$

Figure 2. Cutting head conical coordinate system [3] 


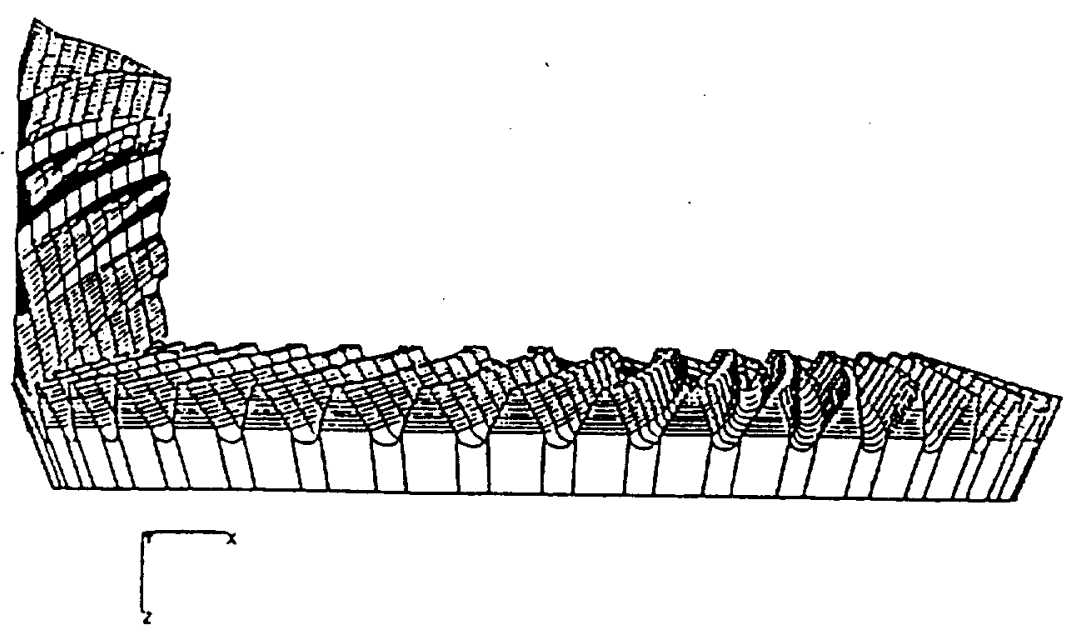

Figure 3. 3-D Model of the Spiral Bevel Gears

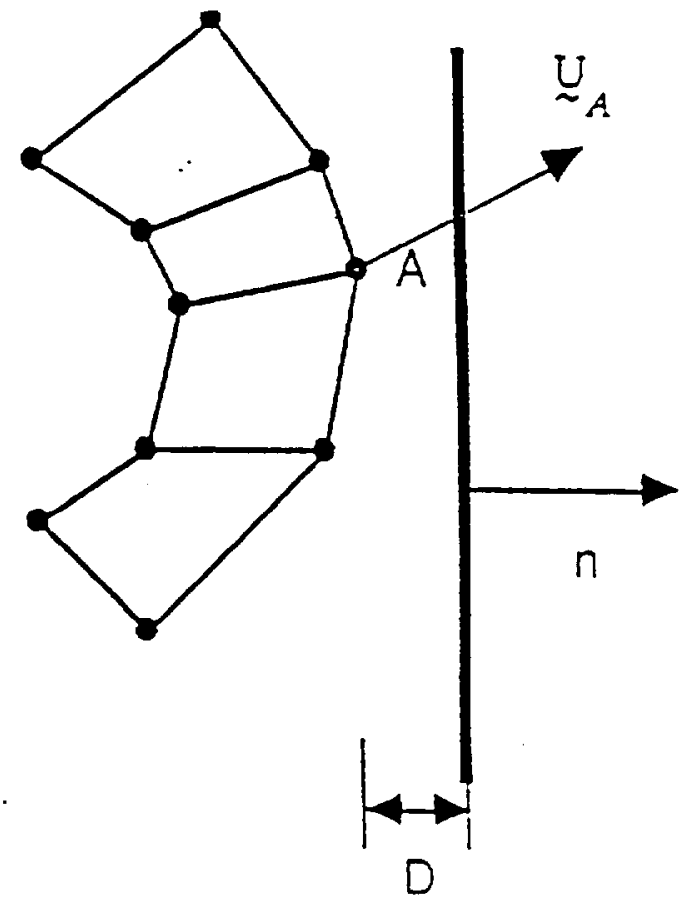

Figure 4. The non-penetration constraint in contact option of reference 11

9 


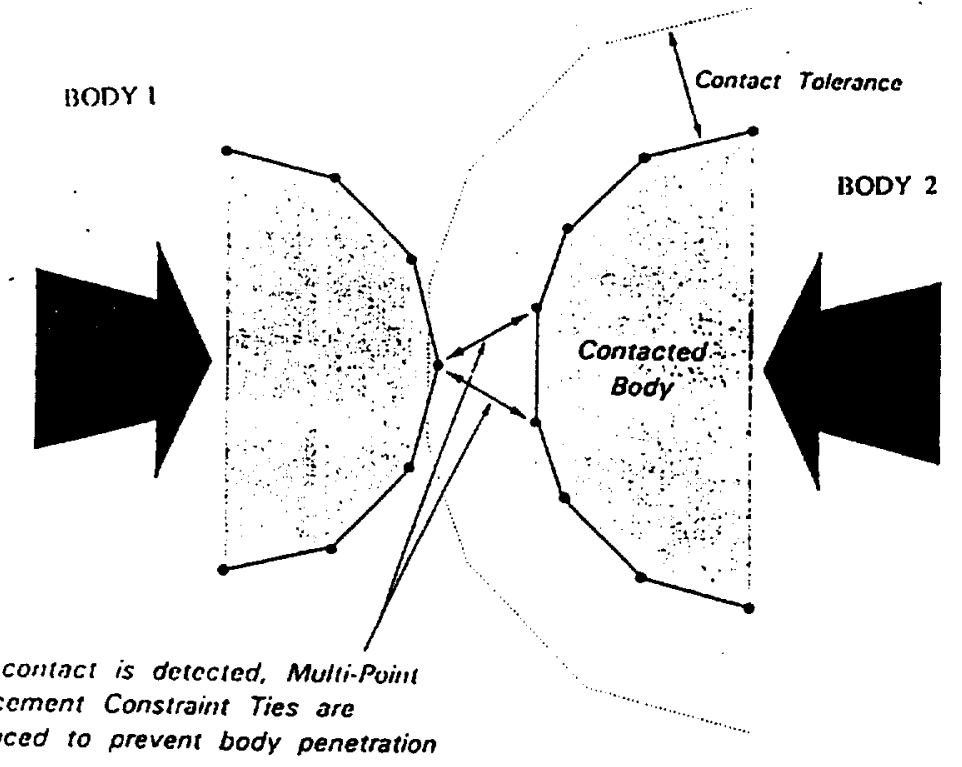

Figure 5. Contact depiction

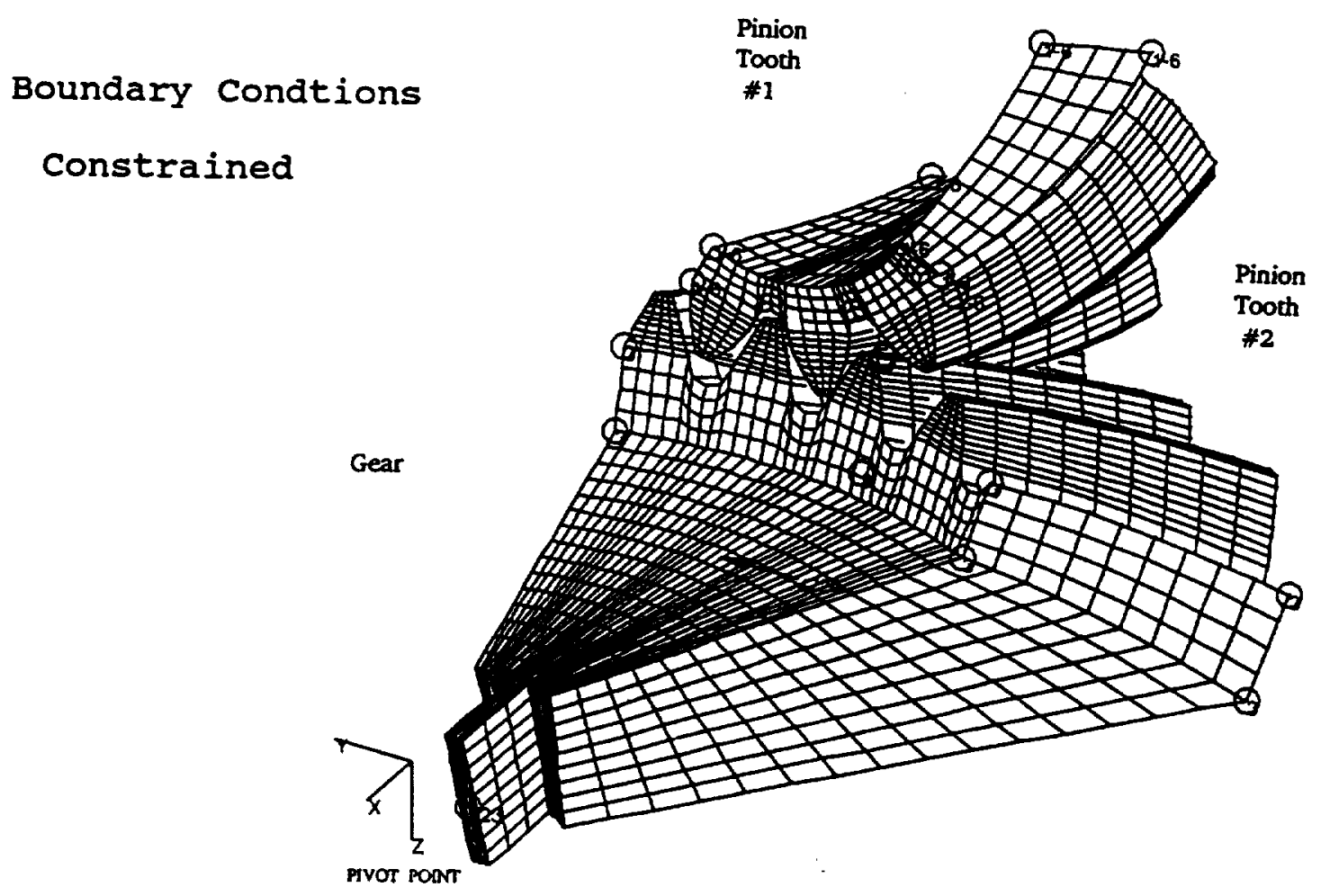

Figure 6 . Seven tooth model with boundary conditions 


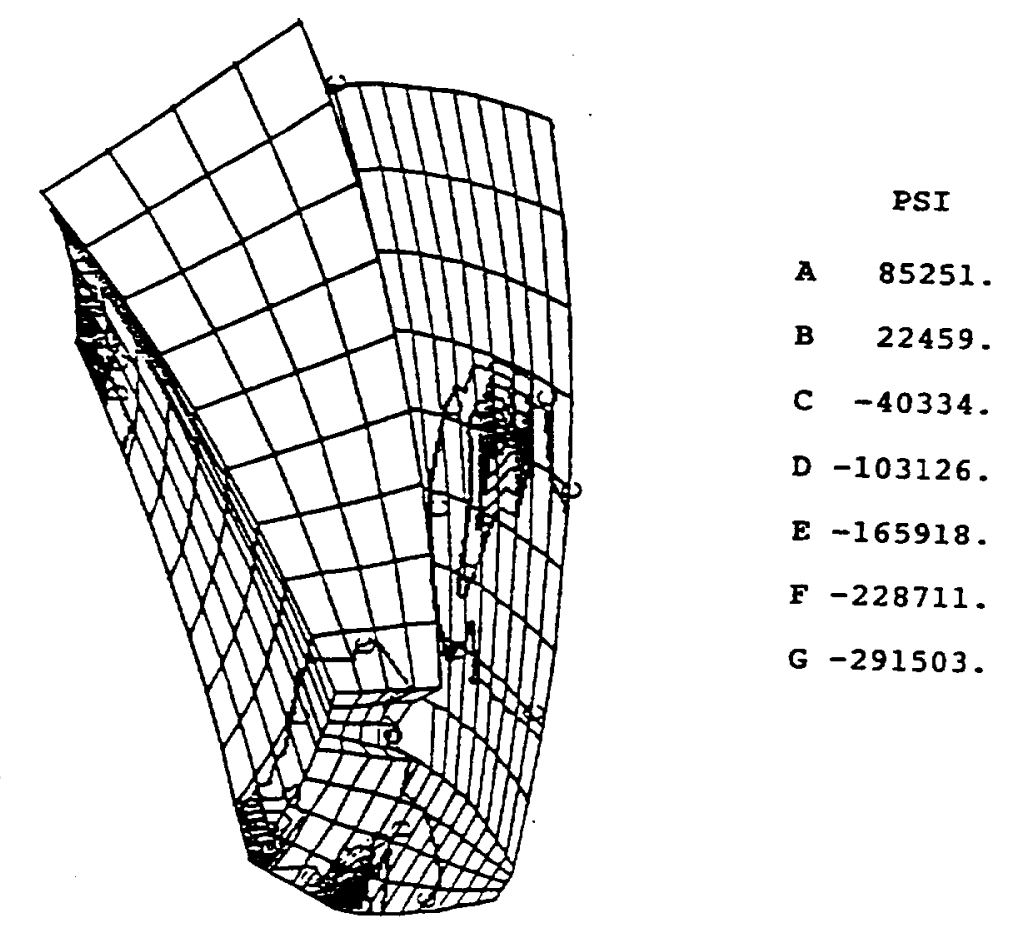

Figure 7. Nodal stress result on pinion obtained from automated contact analysis in seven tooth model

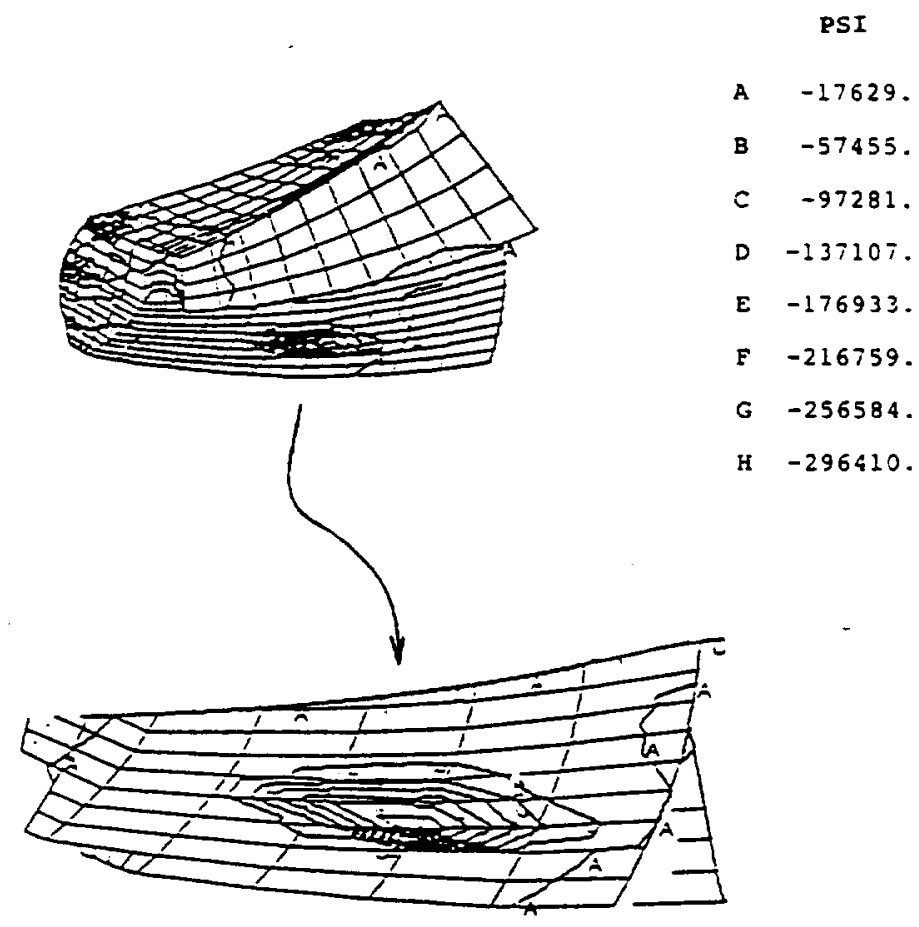

Figure 8. Nodal stress Result on Pinion Obtained From the Gap Element Solution and Seven Tooth Model 
Public reporting burden for this collection of information is estimated 10 average 1 hour per response, including the time for reviewing instructions, searching existing data sources, gathering and maintaining the data needed, and completing and reviewing the collection of information. Send comments regarding this burden estimate or any other aspect of this colvertion of information including suggestions for reducing this burden, to Washington Headquarers Services, Directorate for Intormation Operations and Reports, 1215 Jefferson Davis Highway, Suite 1204, Arlington, VA 22202-4302, and to the Oftice of Management and Budget, Paperwork Reduction Project (0704-0188). Washington, DC 20503.
1. AGENCY USE ONLY (Leave blank)
2. REPORT DATE
June 1994
3. REPORT TYPE AND DATES COVERED
Technical Memorandum

\section{TITLE AND SUBTTTLE \\ Comparison of Gap Elements and Contact Algorithm for 3D Contact Analysis of Spiral Bevel Gears}

\section{AUTHOR(S)}

G.D. Bibel, K. Tiku, A. Kumar, and R. Handschuh
WU-505-62-36

1L162211A47A

5. FUNDING NUMBERS REPORT NUMBER

E-8947

and

Vehicle Propulsion Directorate

U.S. Army Research Laboratory

Cleveland, Ohio 44135-3191

9. SPONSORING/MONITORING AGENCY NAME(S) AND ADDRESS(ES)

National Aeronautics and Space Administration

Washington, D.C. 20546-0001

and

U.S. Army Research Laboratory

Adelphi, Maryland 20783-1145

10. SPONSORING/MONITORING

AGENCY REPORT NUMBER

NASA TM-106643

ARL-TR-478

AIAA-94-2936

11. SUPPLEMENTARY NOTES

Prepared for the 30th Joint Propulsion Conference cosponsored by the AIAA, SAE, ASME, and ASEE, Indianapolis, Indiana, June 2729, 1994. G.D. Bibel, University of North Dakota, P.O. Box 8063, Grand Forks, North Dakota 58202; K. Tiku and A. Kumar, University of Akron, Akron, Ohio 44309; R. Handschuh, Vehicle Propulsion Directorate, U.S. Army Research Laboratory, NASA Lewis Research Center. Responsible person, R. Handschuh, organization code 2730, (216) 433-3969.

\begin{tabular}{l|l} 
12a. DISTRIBUTIONAVAILABILITY STATEMENT & 12b. DISTRIBUTION CODE
\end{tabular}

Unclassified - Unlimited

Subject Category 37

\section{ABSTRACT (Maximum 200 words)}

Three dimensional stress analysis of spiral bevel gears in mesh using the finite element method is presented. A finite element model is generated by solving equations that identify tooth surface coordinates. Contact is simulated by the automatic generation of non-penetration constraints. This method is compared to a finite element contact analysis conducted with gap elements.

\begin{tabular}{|l|l|}
\hline & $\begin{array}{c}\text { 15. NUMBER OF PAGES } \\
13\end{array}$ \\
\cline { 2 - 2 } & $\begin{array}{c}\text { 16. PRICE CODE } \\
\text { A03 }\end{array}$ \\
\hline $\begin{array}{c}\text { 19. SECURITY CLASSIFICATION } \\
\text { OF ABSTRACT } \\
\text { Unclassified }\end{array}$ & $\begin{array}{l}\text { 20. LIMITATION OF ABSTRACT } \\
\end{array}$
\end{tabular}

